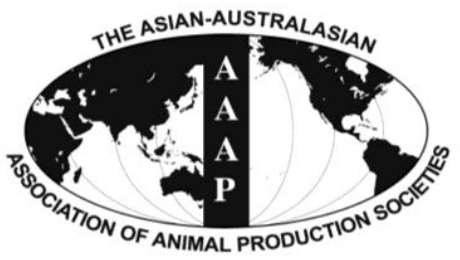

Asian Australas. J. Anim. Sci.

Vol. 26, No. 10 : 1490-1495 October 2013

http://dx.doi.org/10.5713/ajas.2013.13208

www.ajas.info

pISSN 1011-2367 elSSN 1976-5517

\title{
Effects of Cooking End-point Temperature and Muscle Part on Sensory 'Hardness' and 'Chewiness' Assessed Using Scales Presented in ISO11036:1994
}

\author{
Keisuke Sasaki*, Michiyo Motoyama, Takumi Narita, and Koichi Chikuni \\ National Institute of Livestock and Grassland Science, \\ National Agriculture and Food Research Organization (NARO), Tsukuba, Ibaraki 305-0901, Japan
}

\begin{abstract}
Texture and 'tenderness' in particular, is an important sensory characteristic for consumers' satisfaction of beef. Objective and detailed sensory measurements of beef texture have been needed for the evaluation and management of beef quality. This study aimed to apply the sensory scales defined in ISO11036:1994 to evaluate the texture of beef. Longissimus and Semitendinosus muscles of three Holstein steers cooked to end-point temperatures of $60^{\circ} \mathrm{C}$ and $72^{\circ} \mathrm{C}$ were subjected to sensory analyses by a sensory panel with expertise regarding the ISO11036 scales. For the sensory analysis, standard scales of 'chewiness' (9-points) and 'hardness' (7-points) were presented to the sensory panel with reference materials defined in ISO11036. As a result, both 'chewiness' and 'hardness' assessed according to the ISO11036 scales increased by increasing the cooking end-point temperature, and were different between Longissimus and Semitendinosus muscles. The sensory results were in good agreement with instrumental texture measurements. However, both texture ratings in this study were in a narrower range than the full ISO scales. For beef texture, ISO11036 scales for 'chewiness' and 'hardness' are useful for basic studies, but some alterations are needed for practical evaluation of muscle foods. (Key Words: Beef, Texture, Sensory Evaluation, ISO11036:1994, Cooking End-point Temperature)
\end{abstract}

\section{INTRODUCTION}

Texture is an important sensory characteristic of muscle foods, such as beef, pork, and chicken. In particular, improvement of 'tenderness' increased consumers acceptance (Huffman et al., 1996; Boleman et al., 1997; Miller et al., 2001). Our previous questionnaire studies on Japanese consumers indicated that there are consumer segments which require 'tenderness' for beef characteristics (Sasaki and Mitsumoto, 2004; Sasaki et al., 2006). Furthermore, the contribution of 'tenderness' on the overall acceptance of beef among Japanese consumers has been estimated as approximately 25\% (Polkinghorne et al., 2011). Therefore, the objective measurement and improvement of beef texture, in particular 'tenderness,' has been a critical issue for meat producers and industries for their profits.

In consumer, 'tenderness' in muscle foods has been generally used without any definition, hence the meanings of 'tenderness' may be different from person to person. For

\footnotetext{
* Corresponding Author: Keisuke Sasaki. Tel: +81-29-838-8690, Fax: +81-29-838-8606, E-mail: ksuk@affrc.go.jp Submitted Apr. 12, 2013; Accepted Jun. 14, 2013; Revised Jun. 19, 2013
}

evaluation and improvement of meat 'tenderness', texture evaluation items with common definition and clarification of 'tenderness' perception in consumers should be investigated. For this purpose, we previously presented that 'chewiness' and 'hardness', which have different meanings as defined in ISO5492:1992, were perceived separately by a trained sensory panel in beef muscles (Sasaki et al., 2010) and that intramuscular fat improves both 'chewiness' and 'hardness' in beef Longissimus muscles (Sasaki et al., 2012).

However, our previous studies could not provide detailed differences in 'chewiness' and 'hardness' between beef samples, because ISO5492 sensory items is quite qualitative. In contrast, ISO11036:1994 provides detailed sensory scales for 'chewiness' and 'hardness' with definitions and reference materials (International Organization for Standardization, 1994). The purpose of this study is to investigate whether the ISO11036:1994 scales for sensory evaluation of 'chewiness' and 'hardness' is applicable or not in beef texture evaluation.

Furthermore, many previous reports have indicated that the muscle part and cooking end-point temperature affect meat texture. However, there has been no report presenting 
the influence of intermuscular difference and cookery changes on sensory 'chewiness' and 'hardness' ratings. Therefore, another aim of this study is to clarify the detailed effects of muscle part and cooking end-point temperature on sensory 'chewiness' and 'hardness' using ISO11036:1994 scales.

\section{MATERIALS AND METHODS}

\section{Sample preparation}

Hence intramuscular fat strongly affects to meat texture, we used lean beef muscle, not marbled beef, as an experimental model sample in this study. Longissimus (LT) and Semitendinosus (ST) muscles from three Holstein steers fed at Minami-Boso City, Chiba Prefecture, Japan, were obtained from a meat packer. Animals were slaughtered at 22-months-old, and muscles were harvested 5 $\mathrm{d}$ after slaughter. Muscle samples were harvested from cold carcasses, vacuum-packed, and stored at $-30^{\circ} \mathrm{C}$ before sensory experiments. Samples were thawed in a refrigerator set at $4^{\circ} \mathrm{C} 1 \mathrm{~d}$ immediately before the sensory test. Samples were formed into $2 \times 2 \times 2 \mathrm{~cm}$ cubes and subjected to heat treatment using a steam convection oven SSC-5DCNU (Maruzen, Co., Ltd., Tokyo) to cooking end-point temperatures such as 60 and $72^{\circ} \mathrm{C}$, which provided different sensory texture characteristics as described previously (Sasaki et al., 2010; Sasaki et al., 2012).

\section{Sensory panel}

Research scientists of the animal products division of the National Institute of Livestock and Grassland Science were recruited as the sensory panel, as with our previous studies (Sasaki et al., 2010; Sasaki et al., 2012). Therefore, these panelists were highly experienced evaluators of meat texture. Panelists were lectured about the scales of 'hardness' and 'chewiness' presented in ISO11036:1994, and were trained using the example foods indicated in the scales as presented in Table 1. The number of panelists was 17 (10 males and 7 females). Immediately before the sensory testing sessions, each panelist was informed that the beef samples were safe for consumption, and each consented to participate in the experiments as a sensory panelist according to Japanese guidelines for sensory evaluation of meat (National Livestock Breeding Center, 2005).

\section{Sensory test}

Sensory tests were performed using an individual booth illuminated by red lighting and maintained by an airconditioner set at $22^{\circ} \mathrm{C}$. The sensory trials were carried out between 3 to $4 \mathrm{pm}$, and the length of each trial was approximately $20 \mathrm{~min}$. Scales of 'hardness' and 'chewiness' presented in ISO11036:1994 (Table 1) were used for the evaluation. Panelists were trained about these scales of 'hardness' and 'chewiness' using the example foods as presented in Table 1. For the sensory test, two samples each were presented to each panelist at each muscle and endpoint temperature. Thus, each panelist tested a total of eight samples in each trial. The sensory trial was conducted three times with muscles from different carcasses in each trial.

\section{Machinery texture measurements}

Warner-Bratzler shear force value (WBSFV) and 'hardness' of Texture Profile Analysis (TPA) were measured in cooked samples subjected to the sensory test. For WBSFV measurements, cores $1.27 \mathrm{~cm}$ in diameter were prepared from cooked muscle cubes and sheared perpendicularly to the muscle fiber orientation using a

Table 1. Scales of 'chewiness' and 'hardness' defined by ISO11036:1994

\begin{tabular}{|c|c|c|c|}
\hline Attributes & Ratings & Definition & Example \\
\hline \multirow[t]{7}{*}{ Chewiness } & 1 & Low-intensity chewiness & Rye bread, fresh and centre cut \\
\hline & 2 & $\uparrow$ & Frankfurter sausages, uncooked \\
\hline & 3 & & Gum drops \\
\hline & 4 & & \\
\hline & 5 & & Starch-based gum drops \\
\hline & 6 & $\downarrow$ & Peanut chews \\
\hline & 7 & High-intensity chewiness & Toffee \\
\hline \multirow[t]{9}{*}{ Hardness } & 1 & Soft & Cream cheese \\
\hline & 2 & $\uparrow$ & Egg white, hard-boiled \\
\hline & 3 & & Frankfurter sausages, uncooked \\
\hline & 4 & & Cheese, processed \\
\hline & 5 & & Olives, green \\
\hline & 6 & & Peanuts, cocktail type \\
\hline & 7 & & Carrots, uncooked \\
\hline & 8 & $\downarrow$ & Peanut brittle, candy part \\
\hline & 9 & Hard & Rock candy \\
\hline
\end{tabular}


Warner-Bratzler V-blade attached to an Instron Universal Testing Machine (Model 5542; Instron Corp., Canton, MA, USA), fitted with a $500 \mathrm{~N}$ compression load cell with a crosshead speed of $250 \mathrm{~mm} / \mathrm{min}$ at room temperature. The peak force values that were measures of the shearing through the centers of the cores were used to determine WBSFV of the samples. TPA 'hardness' measurements were performed as described (Caine et al., 2003) with some modifications. For TPA hardness, cylindrical samples with $1.27 \mathrm{~cm}$ diameter and $1.0 \mathrm{~cm}$ height were prepared from cooked muscle cubes. The samples were compressed parallel to the muscle fiber orientation using a $4.0 \mathrm{~cm}$ diameter disc type probe attached to a testing machine as described above at room temperature. Each sample underwent two cycles of $80 \%$ compression using the Texture Profile Analysis Test Method Templates (version 3.0; Instron Corp., Canton, MA, USA) with the Instron Testing Machine, and TPA 'hardness' was calculated. For each machinery measurement, 5 replications were conducted for each cooking temperature of each muscle of each carcass. The mean value of 5 replications of each muscle of each carcass was applied to the statistical analysis.

\section{Statistical analysis}

Statistical analysis was performed using the SAS system (version 9.12; SAS Institute, Cary, NC, USA). Sensory scores for 'chewiness' and 'hardness' were analyzed by analysis of variance (ANOVA) using MIXED procedure. Muscles and cooking temperatures were used as the fixed effects and panelists and carcasses were used as the random effects. For ANOVA instrumental WBSFV and TPA 'hardness', MIXED procedure of the SAS system was also used, muscles and cooking temperatures were used as the fixed effects, and carcasses were used as the random effect. Comparisons of least squares means were analyzed by Tukey-Krammer test using LSMEANS option of the MIXED procedure for both sensory scores and machinery texture indices. Correlation analysis between sensory scores for ISO11036 'chewiness' and 'hardness' versus instrumental measurements such as WBSFV and TPA 'hardness' were analyzed using CORR procedure of the SAS system.

\section{RESULTS}

\section{Sensory test}

Effects of the muscle part, cooking end-point temperature and interaction of muscle partxend-point temperature on sensory scores for 'chewiness' and 'hardness,' assessed by a trained sensory panel using ISO11036:1994 scales, were presented in Table 2. Both ISO11036 'chewiness' and 'hardness' scores were significantly higher in ST muscle than those in LT muscle
Table 2. Effects of muscle part and cooking end-point temperature on sensory ratings defined in ISO11036:1994

\begin{tabular}{lcc}
\hline \multirow{2}{*}{ Effects } & \multicolumn{2}{c}{ Sensory attributes } \\
\cline { 2 - 3 } & Chewiness & Hardness \\
\hline Muscle part & $* * *$ & $* * *$ \\
$\quad$ Longissimus & $3.91 \pm 0.25$ & $4.24 \pm 0.21$ \\
Semitendinosus & $5.65 \pm 0.25$ & $5.56 \pm 0.21$ \\
Cooking end-point temperature & $* * *$ & $* * *$ \\
$60^{\circ} \mathrm{C}$ & $4.50 \pm 0.25$ & $4.51 \pm 0.21$ \\
$72^{\circ} \mathrm{C}$ & $5.06 \pm 0.25$ & $5.29 \pm 0.21$ \\
Musclexend-point temperature & $\mathrm{ns}$ & $\mathrm{ns}$ \\
\hline
\end{tabular}

Values were expressed as least squares means \pm SEM.

$* * * \mathrm{p}<0.001 . \mathrm{ns}=$ Not significant $(\mathrm{p}>0.05)$.

$(\mathrm{p}<0.001)$. Samples cooked at a $72^{\circ} \mathrm{C}$ of end-point temperature had higher ISO11036 'chewiness' and 'hardness' ratings than samples cooked at a $60^{\circ} \mathrm{C}$ end-point temperature $(\mathrm{p}<0.001)$. However, muscle parts and cooking end-point temperatures did not significantly interact in both ratings $(\mathrm{p}>0.05)$

\section{Machinery texture measurements}

Effects of the muscle part, cooking end-point temperature and interaction of muscle part×end-point temperature on machinery texture indices such as WBSFV, and 'hardness' of TPA, were presented in Table 3. Both WBSFV and TPA 'hardness' in ST muscle were significantly higher than those in LT muscle $(p<0.001)$. Cooking end-point temperatures also significantly affected both machinery measurements. Both WBSFV and TPA 'hardness' increased significantly between $60^{\circ} \mathrm{C}$ and $72^{\circ} \mathrm{C}$ cooking end-point temperatures $(\mathrm{p}<0.001)$. Furthermore, Table 3 also showed that interaction between muscle parts and cooking end-point temperatures was statistically significant in WBSFV $(\mathrm{p}<0.01)$ As indicated in Figure 1, WBSFV significantly increased in LT muscle by increasing

Table 3. Effects of muscle part and cooking end-point temperature on instrumental texture characteristics

\begin{tabular}{lcc}
\hline & \multicolumn{2}{c}{$\begin{array}{c}\text { Machinery texture } \\
\text { characteristics }\end{array}$} \\
\cline { 2 - 3 } Effects & $\begin{array}{c}\text { Warner-Bratzler } \\
\text { shear force } \\
\text { value }(\mathrm{N})\end{array}$ & $\begin{array}{c}\text { Hardness } \\
\text { (Texture profile } \\
\text { analysis) }(\mathrm{N})\end{array}$ \\
\hline Muscle part & $* * *$ & $* * *$ \\
Longissimus & $23.7 \pm 0.7$ & $60.3 \pm 2.4$ \\
Semitendinosus & $36.6 \pm 0.7$ & $76.2 \pm 2.4$ \\
Cooking end-point temperature & $* * *$ & $* * *$ \\
$60^{\circ} \mathrm{C}$ & $27.2 \pm 0.3$ & $58.1 \pm 2.4$ \\
$72^{\circ} \mathrm{C}$ & $33.1 \pm 0.3$ & $78.4 \pm 2.4$ \\
Musclexend-point temperature & $* *$ & $\mathrm{~ns}$ \\
\hline
\end{tabular}

Values were expressed as least squares means \pm SEM.

$* * * \mathrm{p}<0.001 ; * * \mathrm{p}<0.01 . \mathrm{ns}=$ Not significant $(\mathrm{p}>0.05)$ 


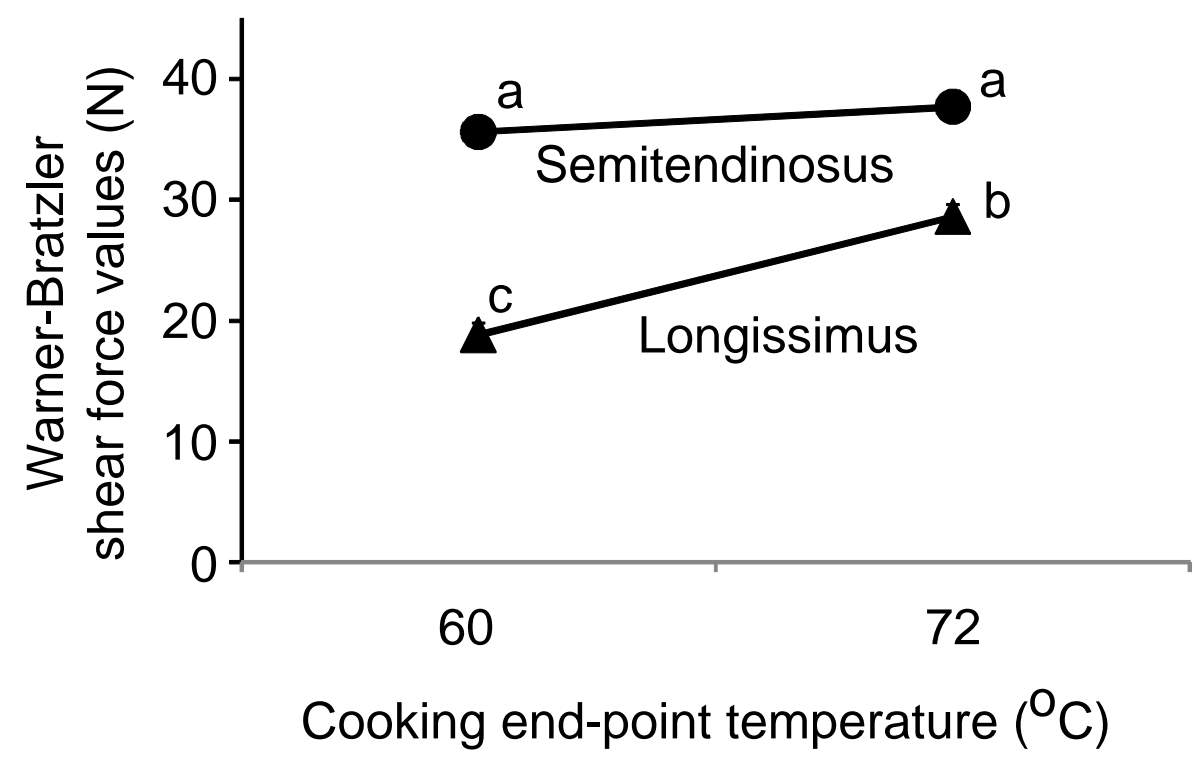

Figure 1. Effects of cooking end-point temperature and muscle position on Warner-Bratzler shear force values. Triangles and circles mean Longissimus and Semitendinosus muscles, respectively. Values are expressed as least squares means \pm SEM. ${ }^{\text {a,b,c }}$ Values with different letters are different at $\mathrm{p}<0.05$.

the cooking end-point temperature from $60^{\circ} \mathrm{C}$ to $72^{\circ} \mathrm{C}$ $(\mathrm{p}<0.05)$, although WBSFV was unchanged in ST muscle between cooking end-point temperatures of $60^{\circ} \mathrm{C}$ and $72^{\circ} \mathrm{C}$.

\section{Correlation between sensory scores and instrumental measurements}

To determine whether or not instrumental measurements such as WBSFV and TPA 'hardness' can explain ISO11036 sensory 'chewiness' and 'hardness' ratings, statistical correlations between sensory scores and instrumental measurements were analyzed $(\mathrm{N}=12)$. WBSFV were significantly and highly correlated with both ISO11036 'chewiness' ( $r=0.911 ; \mathrm{p}<0.001)$ and ISO11036 'hardness' $(\mathrm{r}=0.894 ; \mathrm{p}<0.001)$. Instrumental 'hardness' measured using TPA method was also correlated significantly to both 'chewiness' ( $r=0.705 ; \mathrm{p}<0.05)$ and 'hardness' $(r=0.828$; $\mathrm{p}<0.001$ ), obtained from a trained sensory panel evaluation using ISO11036 standard scales.

\section{DISCUSSION}

It has been generally understood that sensory texture characteristics among muscle positions vary. Shackelford et al. (1995) presented the variation of sensory texture characteristics in 10 major muscles of beef. In particular, different sensory texture characteristics between LT and ST were reported previously. For example, Otremba et al. (1999, 2000) reported that sensory ratings for 'chewiness', which was defined as 'the number of chews necessary to reduce the sample to a consistency ready for swallowing', and overall tenderness were lower in Longissimus Lumbarum (LL) muscle than in ST muscle at $71^{\circ} \mathrm{C}$.
Shackelford et al. (1995) also presented that overall tenderness in LL was higher than that in ST muscle. Our results finding that ISO11036 sensory ratings of both chewiness and hardness in LT muscles were lower than those in ST muscles (Table 2) support previous studies regarding intermuscular differences of sensory texture characteristics.

Cooking end-point temperature is an important factor for meat texture, which deeply relates to the heat denaturation of muscle proteins. In particular, a large heat transition due to protein denaturation has been observed in beef muscle between 60 and $70^{\circ} \mathrm{C}$ using differential scanning calorimetry (Findlay et al., 1986). Increasing the cooking end-point temperature from 60 to $70^{\circ} \mathrm{C}$ raised WBSFV in beef LT muscles (Findley et al., 1986; Sasaki et al., 2012) and machinery shear force (Mathevon et al., 1995). Machinery chewiness and hardness assessed by TPA also increased between 60 and $70^{\circ} \mathrm{C}$ in beef ST muscles (Palka and Daun, 1999). Furthermore, sensory texture changes between 60 to $70^{\circ} \mathrm{C}$ have been well investigated in beef muscles. For example, between 60 and $70^{\circ} \mathrm{C}$, sensory 'tenderness' decreased (Findley et al., 1986) and sensory 'toughness' increased (Tornberg, 2005). Increasing of cooking temperature increased total chewing to above $63^{\circ} \mathrm{C}$ (Martens et al., 1982) and chewing-time above $60^{\circ} \mathrm{C}$ (Mathevon et al., 1995). In this study, both chewiness and hardness ratings using ISO11036 (Table 2) increased between 60 and $72^{\circ} \mathrm{C}$, supported with the machinery texture characteristics such as WBSFV and TPA hardness (Table 3).

Following from these results, because sensory evaluation using ISO11036 scales for 'chewiness' and 'hardness' detected differences caused by cooking end-point 
temperature and muscle position, we considered that the sensory evaluation procedures for 'chewiness' and 'hardness' using ISO11036 has potential for quantitative texture characterization of beef in basic studies.

On the other hand, quantitative evaluation of sensory texture has been required for improvement of 'tenderness' in beef, in order to satisfy consumers' preference. There have been several studies conducted for the objective sensory evaluation of meat texture. For example, Otremba et al. (2000) established the descriptive texture profile sensory panel and the descriptive attribute sensory panel for meat texture evaluation, and evaluated texture items defined by the workers. They used 15-pt scales for each texture attribute with 1 to 3 reference products for each attribute presented to panelists. Braghieri et al. (2012) developed preparation schemes for reference samples of meat sensory characteristics including chewiness/tenderness. They established 3 reference products for each sensory attribute for 100-pt evaluation scales. ISO11036:1994 provides 7and 9-pt scales with 6 and 9 reference products for 'chewiness' and 'hardness' evaluation, respectively (Table 1). However, sensory scores for 'chewiness' and 'hardness' (Table 2) fallen within narrow ranges such as 3.91 to 5.65 for 'chewiness' and 4.24 to 5.29 for 'hardness', in this study. In previous studies regarding quantitative sensory evaluation of meat texture (Otremba et al., 2000; Braghieri et al., 2012), evaluation scales were constructed focusing on meat, and were accurate for meat texture studies. In contrast, ISO11036 scales for 'chewiness' and 'hardness' established for various foodstuffs, not only for meat. Alteration of these ISO11036 scales may be needed for practical meat texture evaluation in further studies, e.g. range limitation and detailed graduation with reproducible reference products.

The relationship between sensory texture characteristics and machinery measurements is also interesting for the objective assessment of meat qualities. In particular, the most commonly used instrumental index for objective meat tenderness is the WBSFV, because the value usually correlates well with sensory tenderness evaluation (Cross, 1987). Our previous study suggested that WBSFV correlated to ISO5492 'chewiness' in terms of beef LT, ST and Psoas Major muscles (Sasaki et al., 2010). In addition, the definition of 'chewiness' in ISO11036:1994 is 'mechanical textural attribute to cohesiveness and to the length of time or the number of chews required to masticate a solid product into a state ready for swallowing', which is deeply related to the breakdown of foodstuffs like the procedure of WBSFV measurement. In the present study, WBSFV highly correlated to ISO11036 'chewiness' ratings rather than to ISO11036 'hardness' scores as described above. In contrast, results in this study also indicated that ISO11036 chewiness ratings and WBSFV were not always parallel. Muscle position and cooking temperature did not interact for ISO11036 chewiness ratings (Table 2), and this result indicated that ISO11036 chewiness increased in both ST and LT muscles at $70^{\circ} \mathrm{C}$ as compared to $60^{\circ} \mathrm{C}$. However, WBSFV was unchanged between 60 and $70^{\circ} \mathrm{C}$ in ST muscles, although WBSFV increased between 60 and $70^{\circ} \mathrm{C}$ in LT muscles (Figure 1). Our previous study also presented that changes in WBSFV between 60 and $70^{\circ} \mathrm{C}$ were different between LT and ST muscles (Sasaki et al., 2010) in which WBSFV increased in LT whereas decreased in ST. WBSFV results in this study has good agreement to our previous study. WBSFV measures a peak force of shearing meat samples using V-blade. In contrast, ISO11036 chewiness has been defined as the amount of work required to masticate a solid product into a state ready for swallowing (International Organization for Standardization, 1994). These difference between 'peak force' in WBSFV and 'amount of work' in ISO11036 chewiness probably due to the non-parallel relationship between WBSFV and ISO11036 chewiness ratings. These results could not establish WBSFV as a decisive instrumental index for ISO11036 'chewiness' ratings. Examination with a greater variety of muscle samples is needed to develop instrumental texture measurements that correspond to sensory texture characteristics measured by internationally established rating scales.

This study aimed to apply the scales for 'chewiness' and 'hardness' defined in ISO11036:1994 to the quantitative and objective measurement of beef texture. We concluded that ISO11036:1994 quantitative scales for 'chewiness' and 'hardness' is a potent tool for basic studies in sensory beef texture, but some alteration should be needed for practical use for beef texture evaluation. A goal of our study is to clarify consumers' perception of meat 'tenderness' using objective sensory texture characteristics. The relationships between consumers' sense of 'tenderness' and 'chewiness' and/or 'hardness' ratings defined in ISO11036:1994 should be investigated in further studies.

Furthermore, instrumental measurements corresponding to ISO11036 'chewiness' and 'hardness' ratings should be developed for the management and improvement of meat texture by meat producers and industries.

\section{ACKNOWLEDGEMENTS}

The work was partially supported by the Japan Society for the Promotion of Science, Grant-in-Aid (KAKENHI) for Young Scientists (B), 21700746, 2009-2010, and 23700898, 2011-2013.

The authors wish to thank Yumiko Endo and Akemi Shimizu from NILGS for their valuable technical assistance. They are also deeply grateful to the research staff from the 
Animal Products Division of NILGS for their generous participation as trained sensory panelists.

\section{REFERENCES}

Boleman, S. J., S. L. Boleman, R. K. Miller, J. F Taylor, H. R. Cross, T. L. Wheeler, M. Koomaraie, S D Shackelford, M. F. Miller, R. L. West, D. D. Johnson, and J .W. Savell. 1997. Consumer evaluation of beef of known categories of tenderness. J. Anim. Sci. 75:1521-1524.

Braghieri, A., N. Piazzolla, A. Carlucci, E. Monteleone, A. Girolami, and F. Napolitano. 2012. Development and validation of a quantitative frame of reference for meat sensory evaluation. Food Qual. Pref. 25:63-68.

Caine, W. R., J. L. Aalhun, D. R. Best, M. E. R. Dugan, and L. E. Jeremiah. 2003. Relationship of texture profile analysis and Warner-Bratzler shear forces with sensory characteristics of beef rib steaks. Meat Sci. 64:333-339.

Cross, H. R. 1986. Sensory characteristics of meat. Part 1 . Sensory factors and evaluation. In: The Science of Meat and Meat Products, 3rd Ed. (Ed. J. F. Price and B. S. Schweigert). Food \& Nutrition Press, Inc., Westport, Connecticut. pp. 307-327.

Findlay, C. J., D. W. Stanley, and E. A. Gullett. 1986. Thermomechanical properties of beef muscle. Meat Sci. 16: 57-70.

Huffman, K. L., M. F. Miller, L. C. Hoover, C. K. Wu, H. C. Brittin, and C. B. Ramsey. 1996. Effect of beef tenderness on consumer satisfaction with steaks consumed in the home and restaurant. J. Anim. Sci. 74:91-97.

International Organization for Standardization. 1994. ISO11036:1994 Sensory analysis - Methodology - Texture profile. International Organization for Standardization, Geneva, Switzerland.

Martens, E., E. Stabursvik, and M. Martens. 1982. Texture and colour changes in meat during cooking related to thermal denaturation of muscle proteins. J. Texture Stud. 13:291-309.

Mathevon, E., L. Mioche, W. E. Brown, and J. Culioli. 1995. Texture analysis of beef cooked at various temperatures by mechanical measurements, sensory assessments and electromyography. J. Texture Stud. 26:175-192.

Miller, M. F., M. A. Carr, C. B. Ramsey, K. L. Crockett, and L. C. Hoover. 2001. Consumer thresholds for establishing the value of beef tenderness. J. Anim. Sci. 79: 3062-3068.
National Livestock Breeding Center. 2005. Guidelines for sensory evaluation of meat. Japan Meat Information Service Center, Tokyo, Japan (in Japanese).

Otremba, M. M., M. E. Dikeman, G. A. Milliken, S. L. Stroda, J. A Unruh, and E. Chambers IV. 1999. Interrelationships among evaluations of beef longissimus and semitendinosus muscle tenderness by Warner-Brayzler Shear Force, a descriptivetexture profile sensory panel, and a descriptive attribute sensory panel. J. Anim. Sci. 77:865-873.

Otremba, M. M., M. E. Dikeman, G. A. Milliken, S. L. Stroda, E. Chambers IV, and D. Chambers. 2000. Interrelationships between descriptive texture profile sensory panel and descriptive attribute sensory panel evaluations of beef Longissimus and Semitendinosus muscles. Meat Sci. 54:325332.

Palka, K. and H. Daun. 1999. Changes in texture, cooking losses, and myofibrillar structure of bovine M. semitendinosus during heating. Meat Sci. 51:237-243.

Polkinghorne, R. J., T. Nishimura, K. E. Neath, and R. Watson. 2011. Japanese consumer categorization of beef into quality grades, based on Meat Standards Australia methodology. Anim. Sci. J. 82:325-333.

Sasaki, K. and M. Mitsumoto. 2004. Questionnaire-based study on consumer requirements for beef quality in Japan. Anim. Sci. J. 75:369-376.

Sasaki, K., M. Mitsumoto, and H. Aizaki. 2006. Classification of consumers' viewpoint for purchasing retail beef package. Nihon Chikusan Gakkaiho 77:67-76 (in Japanese).

Sasaki, K., M. Motoyama, J. Yasuda, T. Yamamoto, M. Oe, T. Narita, M. Imanari, S. Fujimura, and M. Mitsumoto. 2010. Beef texture characterization using internationally established texture vocabularies in ISO5492:1992: Differences among four different end-point temperatures in three muscles of Holstein steers. Meat Sci. 86:422-429.

Sasaki, K., M. Motoyama, and T. Narita. 2012. Increased intramuscular fat improves both 'chewiness' and 'hardness' as defined in ISO5492:1992 of beef Longissimus muscle of Holstein $\times$ Japanese Black F1 steers. Anim. Sci. J. 83:338-343.

Shackelford, S. D., T. L. Wheeler, and M. Koohmaraie. 1995. Relationship between shear force and trained sensory panel tenderness ratings of 10 major muscles from Bos indicus and Bos taurus cattle. J. Anim. Sci. 73:3333-3340.

Tornberg, E. 2005. Effects of heat on meat proteins - Implications on structure and quality of meat products. Meat Sci. 70:493508 